\title{
Comprehensive Examination on Solar -Wind Energy Systems Grid Integration and Emerging Power Quality challenges
}

\author{
Suresh Palla, Jarupula Somlal
}

\begin{abstract}
Sources of energy for conventional power generation are limited and depleting ceaselessly owing to rising demand of power because of the social modernization, rising industrial growth, quick rate of infrastructure development and also technological innovation. Several developed countries have started the employment of renewable energy sources considerably to attenuate the greenhouse gases effects within the atmosphere and harmful emission. The rising demand of the power without any harmful and damaging issue, forces the eye of researchers towards renewable sources (like wind and solar) of energy. Therefore, it's minimum impact on the atmosphere. Renewable Energy sources are becoming the key contributors in the present society due to the increasing cost of oil products and decrease in the price of RES. By using natural resources energy sources like Solar and wind are providing green energy. Renewable Energy penetration is increasing worldwide day by day. Renewable power generation will introduce noticeable power quality challenges when integrated to power grid. From the aspect of RES, renewable energy generation is intermittent and non-dispatchable because of varied nature of RES. The most common $P Q$ challenges on $R E$ integration are frequency and voltage fluctuations in the power system caused by noncontrollable atmospheric condition and Harmonics that are introduced because of power electronic converters used in RE power generation. This paper presents an intensive literature review, conducted on emerging $P Q$ issues owing to Solar and Wind energy systems integration and existing mitigation methods.
\end{abstract}

Keywords : Renewable Energy, Solar, Wind, Power Quality, Grid Integration, Voltage fluctuations, Frequency fluctuations and Harmonics.

\section{INTRODUCTION}

Solar and Wind energy sources are becoming alternative resources in present power generation as conventional sources of energy for power generation are scattered across the world. India may be a country of continental size and this can be useful in reconciliation the variable output of RES situated in some states by integrating them into all Indian power grids. As on March 2018 RES integrated power generation is $55796 \mathrm{Mw}$ i.e. $27.31 \%$ of total available power. MNRE (Ministry of New and Renewable Energy), Govt. of India is aiming to attain $100 \mathrm{GW}$ of solar and $60 \mathrm{GW}$ of wind power by 2022. Solar and Wind are thought-about to be the major sources of renewable energy power generation, and

Revised Manuscript Received on September 22, 2019

* Correspondence Author

Suresh Palla *, Ph.D scholar, Dept. of EEE, K L E F Deemed to be University, Guntur, Andhra Pradesh, India.

Dr. Jarupula Somlal, Professor Dept. of EEE, K L E F Deemed to be University, Guntur, Andhra Pradesh, India they are growing at a quicker rate for the past two decades. Over last few years power generation through RES forms a major part of the overall power generation within power system.

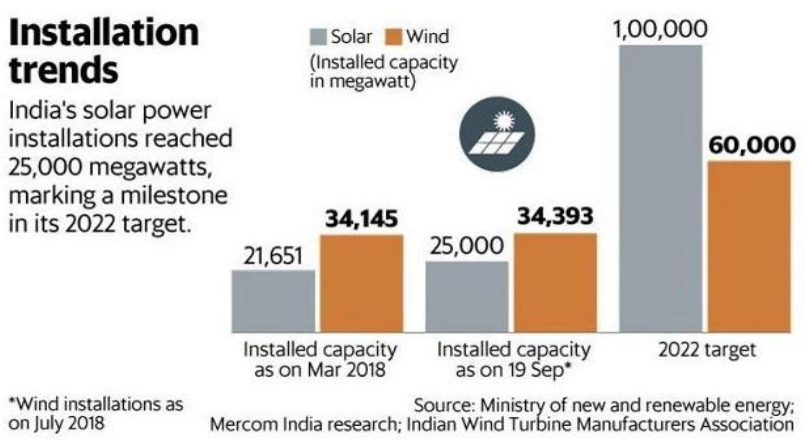

Figure 1: Installed capacity of Solar and Wind Energy in India as on 2018

(Source: Ministry of New and Renewable Energy)

As renewable energy is intermittent, distributed and independently controlled, therefore, adapting power grids to control with RES are often very sophisticated. The way to improve power quality, reliability and energy efficiency for future smart grid are vital considering the potential immense investment over coming decades on expanding and maintaining power system to take in RE power generation. It has noticed that grid connected RES will introduce PQ problems to power system [1]. Power generation through RES is intermittent with high fluctuations because of variable nature of RES. As RE penetration level increases over time, those high fluctuations produce serious PQ issues [2]. From power system aspect, generation and load changes will result in frequency variations and short circuit faults introduce voltage sags, these will interact with integrated RES that produce more sophisticated and uneven operational conditions. Power Quality among several different factors, seems to be one in all the foremost vital features that might have an effect on the reliability and stability of tomorrow's power system [3]-[4].

This paper organized in the way that, power quality challenges associated with RES integration are summarized in section II. Various techniques for improving power quality in grid connected RES are reviewed in Section III, in section IV the role of electrical energy storage system in power quality improvement is discussed and conclusions in section $\mathrm{V}$. 


\section{PQ CHALLENGES ON INTEGRATION OF WIND AND SOLAR ENERGY SYSTEMS}

Integration of Wind and Solar energy systems will introduce Harmonics, due to power electronic interface and Voltage and Frequency variations, caused by variable nature of the mentioned sources and disturbances from power grid side [3].

2.1. Renewable Energy Side: Due combination of Solar and Wind systems to power grid [5], the output becomes intermittent due to the nature of RES like uncontrollable variability and partial unpredictability. Once daylight varies and wind accelerates, the output varies consequently which ends up with variations in frequency and voltage on transmission side of the grid. Such fluctuation wants frequency regulation and voltage support. Characteristics of droop used significantly for DFIGs [6] to regulate voltage and frequency magnitudes. Voltage quality also can be enhanced by interfacing the power system grid with adaptive controllers. Convenience of daylight and wind will be foreseen using weather and generation forecasting technologies. At lower level of penetration, PQ problems are at local grid and device level, therefore resolution is now typically equipment specific whereas at higher levels of penetration, grid technologies are required. Development within the technologies perspective is must for the renewable energy to take part in future developments.

2.2. Power Grid Side: Nonlinear loads connected on the power grid affects renewable energy integration, operation of sensitive loads which are connected to grid will be affected due to voltage quality issues like sag and swell, from the reviewed literature the $\mathrm{PQ}$ challenges because of grid connected RES are power fluctuations, frequency fluctuations, voltage fluctuations and harmonics [3],[7].

2.2.1. Fluctuations in Power: As power from wind turbine is proportional to the cube of wind speed when ever speed varies generated power will vary accordingly. The power quality problems because of wind power fluctuations including reactive and active power generation fluctuations trigger flickering at the PCC grid frequency fluctuations and accumulated instability in grid. This will transmission line power swings there by incapable of meeting load demands [7]. Large wind penetration into power grid will demand larger reserve power throughout low speed conditions.

2.2.2. Fluctuations in Voltage: Variable wind speed will cause fluctuations in output voltage at PCC. System operation will get affected by this voltage variation. Unbalance at the PCC and size of the voltage variation is additionally obsessed with the short circuit level of power and system resistance. It implies consequences of fluctuations in voltage are additional evident in weak utility grids, significant reduction in lifetime of equipment which are connected to the grid due to these fluctuations in voltage. The system voltage fluctuations are classified as voltage sag, swell, flicker and unbalance [8].

2.2.3. Fluctuations in Frequency: Power imbalances in the middle of supply and demand in the power system lead to fluctuations in frequency. Frequency will be regulated throughout such disturbances as a result of synchronous generators will use large quantities as a result of inertia stored K.E form their large size masses of rotation. K.E discharged or absorbed in recompense for the unbalance in electrical and mechanical power of those generators. [9]. In Alternator, by controlling excitation voltage can be controlled and by controlling mechanical power input frequency can be controlled. When frequency fluctuates due to disturbance, the system inertia counters the initial frequency fluctuation till it frequency restored to steady-state value. Grid interfaced power electronic converters will offer zero inertia as they are static devices. With high penetration of wind will reduce equivalent rotational inertia of the system. Equivalent rotational inertia and frequency are inversely proportional to each other it means with high penetration of renewable energy may reduce the inertia so the frequency stability will get degraded [10].

2.2.4. Harmonics: Because of nonlinear loads and grid interfacing $\mathrm{PE}$ converters distortion of voltage and current waveforms in power system takes place [11]. Switching operation of power electronic interfacing inverters in Solar and Wind energy conversion systems will also contribute to harmonics. THD at the point of inter connection mainly depends on design, topology and control method of grid interfaced inverter.

\section{TECHNIQUES FOR POWER QUALITY IMPROVEMENT IN GRID INTERFACED RENEWABLE ENERGY CONVERSION SYSTEMS}

\subsection{Grid connected Wind Energy Technology Review:}

During last fifteen years wind power generation technology has undergone a tremendous transformation, wind power generation is completely different from power generation by conventional sources of energy with Synchronous Generators. However, introduction of asynchronous generators for wind power generation is more advantageous when compare with conventional generators. Intermittent nature of wind may introduce PQ problems like Voltage and Frequency fluctuations, and lower power factor. By absorbing reactive power from the grid DFIGs may cause lower power factor, system will become unstable if too much absorption of reactive power from the system, this leads to damage of end user equipment. All these aforementioned power quality problems due to WECS

Can be addressed at the point of interconnection (POI) to the power grid [12]-[13]. 


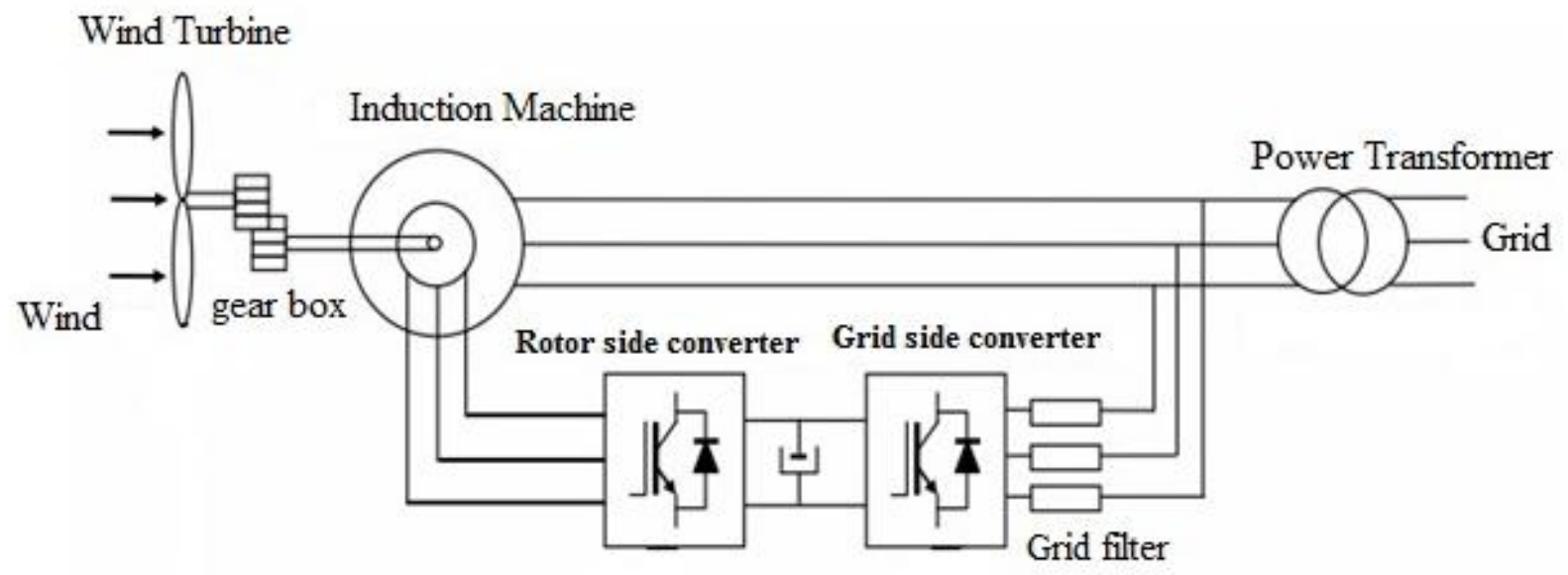

Figure 2: Grid connected Wind Energy System.

An enhanced PLL based controller was implemented by Bhim Singh for a voltage and frequency controlled three phase four wire WECS [14].

The effect of Grid-Connected WECS with distributed static compensator has been demonstrated by Madhusudhan Singh. The proposed topology addressed voltage regulation, harmonics and load imbalance for different operating conditions. Grid current total harmonic distortion was also shown, for grid side inverter (VSC) to generate gate pulses PWM Hysteresis current controller is used [15].

Grid connected PMSG based wind turbine to mitigate harmonics and ability to compensate reactive power at the PCC, was implemented by M. Singh and V. Khadkikar. This topology consists of shunt and series converters with same dc link capacitor; mitigation of harmonics and compensation of reactive power have been addressed by grid side converter where as extraction of maximum power addressed by generator side converter. Proposed topology controlled by using Synchronous reference frame theory [16].

Novel controller based integrated STATcom-Battery energy storage system for WECS in grid interconnected mode was implemented by L. Ashok Kumar and Dr. V. Indragandhi. In the proposed system to improve power factor and to mitigate harmonics, Hysteresis PWM current controller is used. Setup based on Matlab-dSPACE DS1104 interface was also employed for experimental results to analyze the working performance of the system [17].

Grid interfaced DFIG based variable speed WECS, implemented by Bhim Singh and N. K. Swami Naidu. [18] The main purpose of the proposed system is for power smoothening and MPPT, rotor position computation algorithm was proposed to achieve the objective.

DFIG based WECS with integrated Active power filter capabilities, was presented by N. K. SwamiNaidu, and B Singh, [19] in this system topology WECS worked as STATCom to supply harmonics when ever wind turbine is in OFF mode. DSP based prototype was also developed for experimental validation of the simulation results.

\subsection{Grid connected Solar PV Technology Review:}

Now a day's renewable energy power generation techniques are grown up and inevitable. Since Solar power generation is pollution free and free availability across the world, this becomes most promising energy. It is beneficial especially in remote and rural areas where the difficulty of transporting fuel and lack of grid lines [20].

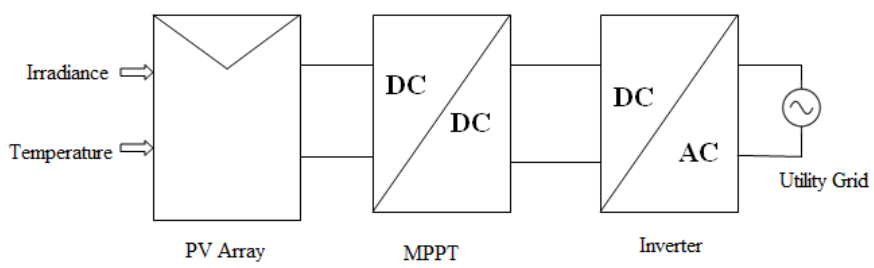

Figure 3: Grid connected Solar PV System.

Francisco A. S. Neves, [21] was presented, Unbalanced Grid Fault Ride- through controlled for Single-Stage PV Inverter, the proposed control scheme able to inject Reactive Power into grid under Voltage unbalance conditions. The space vector Fourier transform based current controller is used to enhance the Power Quality.

Grid interfaced solar PV power generation controlled by Neural Network was introduced by Bhim Singh, and Arun kumar verma [22].

Sandia National Laboratories (SNL), USA analyse performance of grid connected on two separate distribution feeders, was presented by Jimmy Quiroz [23].

Sachin Devassy, and Bhim Singh, [24] Have implemented and Analyzed the performance of 3-Phase Solar PV Integrated Unified power quality conditioner. Proposed scheme consists of series and shunt compensators connected back-back with same DC link, shunt converter will extract maximum power from PV along with load current harmonic compensation whereas series converter will takes care about the voltage injection into the grid. An improved SRF theory was implemented to achieve the objective.

PV-UPQC-S has been demonstrated by Sachin Devassy, and Bhim Singh, based on modified PQ theory [25]. In this proposed scheme positive sequence components of 
voltage with fundamental frequency at PCC. Generalized cascaded delay signal cancellation technique along with PQ theory is used to estimate reference signals for the PVUPQCS.

Sachin Devassy [26] integrated Solar PV with UAPF with Novel controller. MSSI (Modified symmetrical sinusoidal integrator) based control algorithm is proposed. Solar PV is fundamental positive sequence voltage and current signal at PCC based on MSSI then used in generation of reference signal for shunt and series active power filter respectively. SAF maintains grid currents sinusoidal and balanced whereas series filter maintains load voltage sinusoidal and balanced.

Ambrish Chandra and Bhim singh [27] have proposed a novel topology of 'Grid connected SECS under grid voltage distortion and imbalance', in this proposed system Incremental Conductance based MPPT algorithm along with unit vector estimation and Neural network based LM-Sixth current control technique was used to eliminate power quality problems and to current conditioning in a weak grid.

\subsection{Grid connected Hybrid Renewable Energy system} Review:

Increasing population and growing industrialization results in more demand of electricity day by day. In order meet this high load demand, power generation from conventional sources is increased which results in more stress on the existing conventional plants. Attention towards usage of non-conventional energy sources like Wind, PV, Biomass, tidal, fuel cell and in hybrid combination may reduce the harmful effects of conventional fuels on the present environment and global warming to overcome the rising need of electricity day by day. [28].

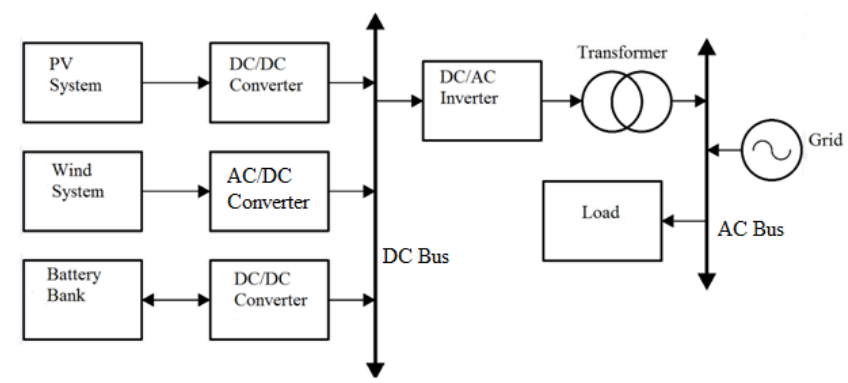

Figure 4: Block diagram of Solar, Wind and battery integrated Grid System.

Grid connected Solar and Wind hybrid generation system with versatile transfer of power capability, presented by Seul-Ki Kim, Jin-Hong Jeon [29]. To operate this hybrid system in different operating modes electromagnetic transient analysis program was used.

Rupesh G. Wandhare, [30] integrated solar PV with large capacity DFIG based wind power system with grid. The proposed modified PV power control algorithm kept system to be stable under high wind velocity and radiation simultaneously.

Grid connected Wind-Solar hybrid power system compensating with shunt active power filter was demonstrated by Vinatha.U [31]. The integrated SAPF directly integrated to dc bus of UAPFPV system, extracted of

controlled by using Id - Iq method to extract harmonics from load current.

Solar wind hybrid energy system with power quality improvement features has presented by Jayasankar V N, [32] the DC Link voltage in the proposed configuration controlled by Fuzzy controller to improve the system performance under nonlinear loads.

\section{ELECTRICAL ENERGY STORAGE}

In emerging IEC-relevant markets EES will become indispensable in the use of RES to achieve reduction in $\mathrm{CO} 2$ emission and for smart grid [33]. EES facilitate three key features like, firstly by storing electricity obtained at off-peak times reduces cost of electricity, flexibility of using power whenever the demand rises instead of buy then at higher prices, secondly improve the reliability of the power supply and stabilize the voltage, frequency and improves the quality of power.

Mahesh K. Mishra, [34]. Proposed A unified energy management scheme, for RES Grid interconnection with battery and supercapacitor hybrid storage system. This configuration will improve the system performance against intermittent nature of RES along with nonlinear loads on the utility grid.

Mahamadou Abdou Tankari, [35] integrated diesel wind hybrid generating system with batteries and ultracapacitors to enhance performance of hybrid system and reduce the consumption of fuel. A lifetime-estimation-based method was proposed to optimize the size of storage device to enhance system performance.

\section{CONCLUSION}

This paper deals with various Power Quality challenges on integration of RES to the utility grid. Serious problems of Power Quality Harmonics, Voltage and Frequency fluctuations are reviewed. Mitigation techniques related to them are identified and latest technologies are discussed. Storage energy systems and their role in improving Power Quality are also reviewed.

\section{REFERENCES}

1. A. S. Anees, "Grid Integration of Renewable Energy Sources Challenges, Issues and Possible Solutions,” 2012 IEEE 5th India Int. Conf. Power Electron., pp. 1-6.

2. D. Lew et al., "How do Wind and Solar Power Affect Grid Operations : The Western Wind and Solar Integration Study Preprint," 2009.

3. Xiaodong Liang, "Emerging power quality challenges due to integration of renewable energy sources," IEEE Trans. Ind. Appl., vol. 53, no. 2, pp. 1-9, 2016.

4. N. Phuangpornpitak and S. Tia, "Opportunities and challenges of integrating renewable energy in smart grid system," Energy Procedia, vol. 34, pp. 282-290, 2013.

5. V. Khare, S. Nema, and P. Baredar, "Solar-wind hybrid renewable energy system: A review,” Renew. Sustain. Energy Rev., vol. 58, pp. 23-33, 2016.

6. V. Kumar, A. S. Pandey, and S. K. Sinha, "Grid integration and power quality issues of wind and solar energy system: A review," Int. Conf. Emerg. Trends Electr. Electron. Sustain. Energy Syst. ICETEESES 2016, vol. 2011, pp. 71-80, 2016. 
7. P. K. Ray, S. R. Mohanty, and N. Kishor, "Classification of power quality disturbances due to environmental characteristics in distributed generation system," IEEE Trans. Sustain. Energy, vol. 4, no. 2, pp. 302-313, 2013.

8. M. A. Saqib and A. Z. Saleem, "Power-quality issues and the need for reactive-power compensation in the grid integration of wind power," Renew. Sustain. Energy Rev., vol. 43, pp. 51-64, 2015.

9. J. G. Ndirangu, J. N. Nderu, and A. M. Muhia, "Power Quality Challenges and Mitigation Measures in Grid Integration of Wind Energy Conversion Systems," 2018 IEEE Int. Energy Conf., pp. 1-6, 2018.

10. S. Singh, R. K. Verma, A. K. Shakya, and S. P. Singh, "Frequency stability analysis of hybrid power system based on solar PV with SMEs unit,” Int. Conf. Emerg. Trends Electr. Electron. Sustain. Energy Syst. ICETEESES 2016, pp. 5-11, 2016.

11. R. Abbassi, M. Hammami, and S. Chebbi, "Improvement of the integration of a grid-connected wind-photovoltaic hybrid system," 2013 Int. Conf. Electr. Eng. Softw. Appl. ICEESA 2013, no. 1, 2013.

12. H. Bindner and P. Lundsager, "Integration of wind power in the powe system," IECON Proc. (Industrial Electron. Conf., vol. 4, pp 3309-3316, 2002.

13. P. S. Georgilakis, "Technical challenges associated with the integration of wind power into power systems," Renew. Sustain. Energy Rev., vol. 12, no. 3, pp. 852-863, 2008.

14. B. Singh and S. Sharma, "Design and implementation of four-leg voltage-source-converter-based VFC for autonomous wind energy conversion system," IEEE Trans. Ind. Electron., vol. 59, no. 12, pp. 4694-4703, 2012

15. M. Aggarwal, S. K. Gupta, and M. Singh, "Analysis and control of grid connected wind energy system with DSTATCOM," 2012 IEEE 5th Power India Conf. PICONF 2012, no. 2, 2012.

16. M. Singh, V. Khadkikar, and A. Chandra, "Grid synchronisation with harmonics and reactive power compensation capability of a permanent magnet synchronous generator-based variable speed wind energy conversion system," IET Power Electron., vol. 4, no. 1, p. 122, 2011.

17. L. Ashok Kumar and V. Indragandhi, "Power quality improvement of grid-connected wind energy system using facts devices," Int. J. Ambient Energy, vol. 0, no. 0, pp. 1-10, 2018.

18. N. K. S. Naidu and B. Singh, "Grid-Interfaced DFIG-Based Variable Speed Wind Energy Conversion System With Power Smoothening," IEEE Trans. Sustain. Energy, vol. 8, no. 1, pp. 51-58, 2017.

19. N. Swami Naidu and B. Singh, "Doubly Fed Induction Generator for Wind Energy Conversion Systems with Integrated Active Filter Capabilities," IEEE Trans. Ind. Informatics, vol. 3203, no. c, pp. 1-1, 2015.

20. R, Gokila, Arunkumar P, Deepakkumar S, Athul Ravi, And Sakthivel S. "Home Automation Using Smart Mirror With Raspberry Pi." international journal of communication and computer technologies 7.supplement 1 (2019), 33-34 print. doi:10.31838/ijccts/07.sp01.08

21. Jegan Diravianath $\mathrm{S}$, Ajith A, Dharaniram $\mathrm{T} S$, Gokulnath M, And Balaji T. "Monitoring and Control of Component Transfer and Packing through Conveyors Using PLC, SCADA and Mobile Application." International Journal of Communication and Computer Technologies 7.Supplement 1 (2019), 35-37. Print doi:10.31838/ijccts/07.SP01.09

22. A. K. Verma, D. T. Shahani, and B. Singh, "Neural network controlled grid interfaced solar photovoltaic power generation," IET Power Electron., vol. 7, no. 3, pp 614-626, 2013

23. J. Quiroz, M. Reno, and S. N. Laboratories, "Detailed Grid Integration Analysis of Distributed PV," 2012 38th IEEE Photovolt. Spec. Conf., pp. 596-601, 2011.

24. S. Devassy and B. Singh, "Design and Performance Analysis of Three-Phase Solar PV Integrated UPQC," IEEE Trans. Ind. Appl., vol. 54, no. 1, pp. 73-81, 2018.

25. S. Devassy and B. Singh, "Modified pq -Theory-Based Control of," vol. 53, no. 5, pp. 5031-5040, 2017.

26. S. Devassy, "Control of Solar Energy Integrated Active Power Filter in Weak Grid System," 2017 7th Int. Conf. Power Syst., pp. 573-578, 2017.

27. R. K. Agarwal, I. Hussain, B. Singh, A. Chandra, and K. Al-Haddad, "Improved power quality of three-phase grid connected Solar Energy Conversion System under grid voltages distortion and imbalances," IEEE Ind. Appl. Soc. 52nd Annu. Meet. IAS 2016, pp. 2-9, 2016.
28. V. N. Jayasankar, M. V. Gururaj, and U. Vinatha, "A study on hybrid Renewable Energy Source interface to the non-ideal grid at distribution level with power quality improvements," 2016 IEEE 6th Int. Conf. Power Syst. ICPS 2016, no. 1, 2016.

29. S. K. Kim, J. H. Jeon, C. H. Cho, J. B. Ahn, and S. H. Kwon, "Dynamic modeling and control of a grid-connected hybrid generation system with versatile power transfer," IEEE Trans. Ind. Electron., vol. 55, no. 4, pp. 1677-1688, 2008

30. A.R.Vijay Babu, V.Rajyalakshmi, K.Suresh, Renewable Energy Integrated High Gain DC-DC Converter with Multilevel Inverter for Water Pumping Applications, Journal of Advanced Research in Dynamical and Control Systems, Volume 9, Issue 1, PP. 172-190, 2017.

31. M. V. Gururaj, U. Vinatha, and V. N. Jayasankar, "Interconnection of wind-solar hybrid Renewable Energy source to the 3 phase-3 wire distribution system along with power quality improvements at the grid side," Proc. 2015 IEEE Int. Conf. Power Adv. Control Eng. ICPACE 2015, pp. 168-172, 2015.

32. V. N. Jayasankar and U. Vinatha, "Implementation of adaptive fuzzy controller in a grid connected wind-solar hybrid energy system with power quality improvement features," 2016 - Bienn. Int. Conf. Power Energy Syst. Towar. Sustain. Energy, PESTSE 2016, no. 1, pp. 1-5, 2016.

33. WhitePaper, "Electrical Energy Storage. White paper. The International Electrotechnical Commission," (IEC), Geneva, Switz., 2011.

34. Rao, B. Venkateswara, et al. "Optimal power flow by Newton method for reduction of operating cost with

35. SVC models." 2009 International Conference on Advances in Computing, Control, and Telecommunication Technologies. IEEE, 2009

36. M. A. Tankari, M. B. Camara, B. Dakyo, and G. Lefebvre, "Use of ultracapacitors and batteries for efficient energy management in wind-diesel hybrid system," IEEE Trans. Sustain. Energy, vol. 4, no. 2 , pp. 414-424, 2013 